\title{
Temporal summation of pain from radiant stimulation
}

\begin{abstract}
DONALD J. DILLON
New York State Psychiatric Institute, Manhattan College and Columbia University, New York, New York 10027
\end{abstract}

Latency thresholds of pricking pain, using radiant thermal stimulation, were obtained. Ten Ss were tested for 10 sessions, and, in each session, single latency determinations were made at each of 10 stimulus intensities. Each intensity was administered to a different spot along the volar surface of S's nonpreferred forearm. Thus, 10 latency thresholds were obtained from each $\mathbf{S}$ at each intensity and each spot. Initial skin temperature was controlled so that a threshold determination was made when skin temperature measured $33.5^{\circ} \pm 0.5^{\circ} \mathrm{C}$. Analysis of variance of the $\log _{10} \mathrm{t}$ (seconds) values revealed a highly significant linearity of regression of $\log t$ on $\log$ intensity, thus confirming the hypothesized inverse and exponential relationship between latency and intensity. The parameters (slope and $x$-intercept) of the curve were discussed. The $x$-intercept may be interpreted as an index of an aversive threshold and could be used as a possible measure of the physiological component of pain.

The dolorimetric technique developed and employed by J. D. Hardy and his coworkers has been shown to be an extremely useful tool in the experimental study of pain. Its chief advantage lies in the precision with which the physical stimulus-at the surface of the skin-can be measured. Its weaknesses have been well publicized (e.g., Beecher, 1959).

There are two psychophysical procedures which have been utilized in dolorimetry. The first, which yields an intensitive measure of pain sensitivity, involves the detection of painful stimulation when various controlled intensities are presented at a fixed stimulus duration $(3.0 \mathrm{sec})$. The second (originated by D'Amour \& Smith in 1941) yields a temporal measurement of pain sensitivity and involves the detection of a transition from subjective warmth or heat to pain. In this case, $S$ terminates a painful stimulus of fixed intensity when it becomes painful, i.e., reacts to a "sensed" pain.

Neither the relationship between the two procedures nor the interdependence of stimulus duration and stimulus intensity have been adequately studied. Wertheimer (1952) described this single-trial technique and stated, in effect, that a simple mathematical transformation permits one to convert from temporal to intensitive units. Hardy, Wolff, and Goodell (1952, pp. 105-106) present pain thresholds obtained under both procedures, but at different levels of stimulus intensity or at different stimulus durations, and a single curve is used to describe the results of both procedures. Data obtained from three Ss reveal that threshold intensity decreases curvilinearly with increased stimulus duration. The resultant curve appears to be exponential in form, but precise mathematical specification is lacking. The authors do, however, present values for rheobase and utilization time, intimating a belief in such an exponential relationship and, incidentally, confirming a finding obtained previously by Bigelow, Harrison, Goodell, \& Wolff (1945).

The psychophysics unit at the University of Stockholm has published some data relevant to the specification of the intensity-duration relationship Frankenhaeuser (1968) found a logarithmic relation between perceived unpleasantness of electrical stimulation and the stimulus duration for supraliminal ("painful") levels of findings they have obtained when testing not only the skin senses but other sense modalities as well.

Dillon (1965) raised the possibility that threshold energy (intensity $x$ duration) and time are exponentially related. Four intensity levels had been employed in that study, so tests for goodness of fit could not be considered as highly reliable. Nevertheless, doubt was cast upon the validity of the model.

The study reported here was undertaken in order to provide sufficient data to specify the model and to compute the parameters for the intensity-time relationship. Because of its single-trial feature, the D'Amour-Smith technique was utilized.

\section{METHOD}

Subjects

Eight male and two female undergraduate seniors volunteered to participate. Each S was carefully instructed as to the criterion for for pain. Ekman, Fröberg, and stimulation. This is in support of pricking pain (Zegers \& Cahill, 1965) and was warned that the prime interest was in the detection of a change in feeling from heat to pain and not in pain tolerance. Because all were already familiar with the technique, only one practice session was utilized.

\section{Apparatus}

The Hardy-Wolff-Goodell dolorimeter (Williamson Development Co.) was employed and carefully calibrated at each experimental session. Stimulus intensities were selected in order to span the range of the apparatus, utilizing the highest intensity level attainable and marching the lowest and highest intensities used in two previous investigations (viz, 100 and $360 \mathrm{mcal} / \mathrm{sec}$ ). The 10 intensities thus used (in terms of $1,000 \times$ $\mathrm{g} \mathrm{cal} / \mathrm{cm}^{2} / \mathrm{sec}$ and abbreviated as $\mathrm{mcal} / \mathrm{sec})$ were $80,100,130,160$, $200,240,280,340,420$, and 500 . The gradually increasing separation between successive stimulus levels was incorporated in order to insure that the response iatencies to any two adjacent stimulus intensities would indeed be different.

A telethermometer (Yellow Springs Instrument Co. Model 43 TD) was used to measure skin temperatures, which, at a time immediately prior to each latency determination, were maintained at a level of $33.5^{\circ} \pm 0.5^{\circ} \mathrm{C}$ throughout the experiment. Room temperature was also monitored and maintained at a cooler than desired level of $22.0^{\circ} \pm 1.0^{\circ} \mathrm{C}$

\section{Procedure}

Each $S$ washed the nonpreferred forearm with soap and water upon coming into the laboratory, since it is more convenient to hold the dolorimeter in the preferred hand. The length of the forearm was carefully measured and recorded. Five pairs of spots along the volar surface were selected at equal distances from wrist to elbow and painted thoroughly with India ink, thus creating the appearance of two parallel rows of black spots. The lateral row was numbered $1-5$ and the medial, 6-10, with 1 and 6 lying closest to the wrist. Stimulation proceeded in numerical order, starting with Spot 1. Each spot was slightly larger than the stimulus area, which was $3.1 \mathrm{~cm}^{2}$.

In nearly all cases, because of painting with the ink and the coolness of the room, skin temperatures were below the desired level. Several stimulations were administered with gradually increasing intensity levels but of insufficient strength to elicit a pain response. When the desired temperature was attained, a single latency threshold was immediately determined and recorded, and $S$ then 
Table 1

Means and SDs of Log Latency and $y^{\prime}$ (Estimated Log Latency) According to Log Intensity. Means are averages for 10 Ss.

\begin{tabular}{ccccc}
\hline mcal $/ \mathrm{cm}^{2}$ & $\begin{array}{c}\text { Log Latency } \\
\text { (Sec) }\end{array}$ & \multicolumn{2}{c}{$\begin{array}{c}\text { Estimated } \\
\text { Log } t\left(\mathbf{y}^{\prime}\right)\end{array}$} \\
\hline 1.903 & $\mathbf{1 . 3 5 0}$ & .101 & $\mathbf{1 . 3 2 8}$ & .105 \\
2.000 & $\mathbf{1 . 1 8 7}$ & .103 & $\mathbf{1 . 1 8 9}$ & .099 \\
2.114 & $\mathbf{1 . 0 2 2}$ & .087 & $\mathbf{1 . 0 2 6}$ & .092 \\
2.204 & .887 & .088 & .897 & .086 \\
2.301 & .742 & .086 & .759 & .080 \\
2.380 & .636 & .089 & .646 & .075 \\
2.447 & .546 & .066 & .550 & .072 \\
2.531 & .438 & .063 & .430 & .067 \\
2.623 & .302 & .063 & .298 & .062 \\
2.699 & .201 & .059 & .189 & .058 \\
\hline
\end{tabular}

proceeded to warm up and test the next spot. Each of the 10 spots was tested in this manner at each session. There were 10 such sessions, with an intersession interval of 1 week.

A permuted balanced square was devised so that any possible effects of contrast between all possible pairs of stimuli could be assessed if necessary. The design was such that each intensity could be presented first or last in order and was equally likely to precede or succeed every other stimulus intensity. There were, therefore, 10 orders of presentation, in each of which all 10 intensities were administered. Each $\mathrm{S}$ was tested in all 10 orders, and each of the orders was utilized in each of the 10 sessions.

\section{RESULTS}

Dillon (1968) reported significant effects of intensity, level of subjective reactivity, and repeated testing upon energy (latency) thresholds in addition to threshold variation according to locus of stimulation. Because of the increased number of spots stimulated in this experiment and the relatively minor contribution of locus to the total experimental variance, session, rather than spot, was designated as the third of the three major variables. Analysis of variance of the $\log t$ values confirmed the significant findings of the previous experiment.

The means and standard deviations of the $\log t$ values at each intensity of stimulation are summarized in Table 1. The decrease in $\log t$ as intensity is increased is quite apparent, as is the sort of stepwise decrease in SD $\log t$. Intensity was the overwhelmingly major factor in the experiment, accounting for $92.2 \%$ of the total variance. The Ss accounted for $4.0 \%$, and, of course, contributed significantly $(p<.001)$ to the total variance.

The analysis of variance also permits an investigator to test for linearity of regression of the dependent upon the independent variable, in this case, the regression of $\log t$ on $\log I$. Sums of squares were computed for linearity of regression ( $1 \mathrm{df}$ ), deviation of the means ( $\log t$ for each $\log I)$ from the regression line ( $8 \mathrm{df}$ ), for the Linear by $S$ interaction ( $9 \mathrm{df}$, the error term for testing linearity), and for the Deviation by $S$ interaction ( $72 \mathrm{df}$ ), the error term for testing deviation. Linearity was highly significant $(F=3890)$, and the deviation was also significant $(F=6.46, p<.001)$. The latter significance disappeared when latencies to the 80 and $100 \mathrm{mcal} / \mathrm{sec}$ stimuli were dropped from the analysis. Separate analyses for each $\mathbf{S}$ revealed significant deviation from linearity $(\mathrm{p}<.001)$ for only one $\mathrm{S}$, and significant effects of the linearity of regression for all 10 Ss $(p<.001)$.

The estimated $\log t$ values $\left(y^{1}\right)$ are also included in Table 1 , together with the standard deviations. These mean values are plotted as the linear function in Fig. 1. This, of course, is the straight line of best fit for the obtained $\log \mathrm{t}$ values-plotted as large points. The vertical lines represent SD $\log t$ at each stimulus intensity.

The linear equation expressing the relationship between $\log t$ and $\log I$ (line of best fit) takes the form: $\log t=$ $4.0532-1.4318 \log \mathrm{I}$, where 4.0532 is the $y$-intercept and 1.4318 is the slope of the line.

It is quite obvious that the straight line underestimates actual log threshold values at the extremes of stimulus intensity and overestimates in the middle range. The greatest deviation of theoretical from observed values occurred when the stimulus intensity was $80 \mathrm{mcal} / \mathrm{sec}$. Nevertheless, the fit is good.

A reliability check was possible. The mean $\log \mathrm{t}$ values for each $\mathrm{S}$ were computed for all stimuli in the first five and in the second five sessions. The resultant Pearson $r$ was +0.933 , indicating good threshold stability across Ss.

The specific parameters for the $\log t: \log$ I relationship are summarized for each $S$ in Table 2 . The $x$-intercept (x) has been included because of its meaning and ease of interpretation and because the $y$-intercept cannot be interpreted. The $x$ value indicates the

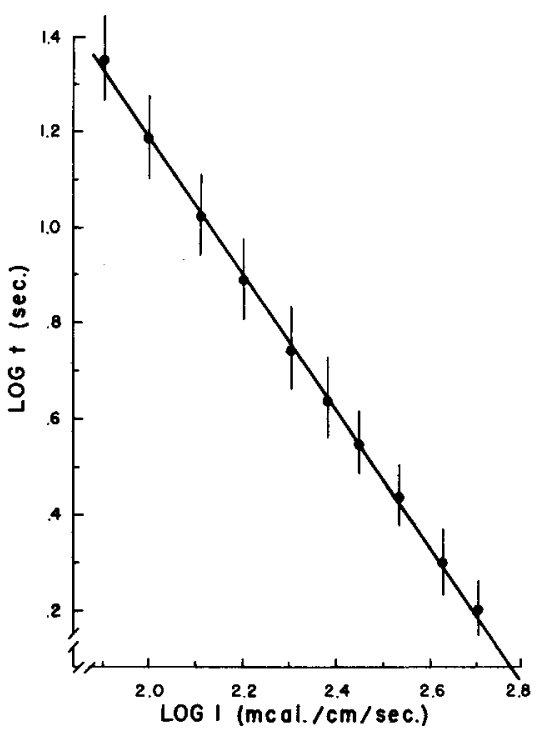

Fig. 1. The time-intensity relationship for pricking pain.

amount of heat necessary to evoke a response latency of $1.0 \mathrm{sec}$. Note the relatively low degree of individual differences for $m$ and $x: V=4.9 \%$ and $1.3 \%$ of the mean, respectively. These two parameters were also checked for reliability by correlating first vs second half (five sessions each) values for the 10 Ss. Pearson $r$ values were $+\mathbf{0 . 6 8 5}$ for $m$ and +0.679 for $x$.

Finally, $m$ and $x$ values were subjected to analyses of variance, with session and $\mathbf{S}$ as the main variables. In each case, Ss data constituted the major source of variation $(42.8 \%$ for $\mathrm{m}$ and $49.7 \%$ for $x$, both $p<.001$ ), but the sessions also significantly influenced the slope $(F=2.90$, $\mathrm{df}=9 / 91, \mathrm{p}<.01$ ) in that $\mathrm{m}$ increased with repetition. The interaction term was used as error estimate.

\section{DISCUSSION}

The major goal of this research was the specification of the latency-intensity relationship for dolorimetry. The relationship was shown to be a linear one between $\log t$ (sec) and log I (mcal/sec).

The fact that the analysis of

Parameters (Slope- $m$, $y$ Intercept $-b$, and $x$ Intercept $-x$ ) Computed for $\log t=b+m \log x$, for 10 Ss. Slope values are negative. Averages are included.

\begin{tabular}{|c|c|c|c|c|c|c|}
\hline \multirow[b]{2}{*}{$\mathbf{s}$} & \multirow[b]{2}{*}{$\mathbf{m}$} & \multirow[b]{2}{*}{ b } & \multirow[b]{2}{*}{$\mathbf{x}$} & & \multicolumn{2}{|c|}{ Averages } \\
\hline & & & & & Mean & SD \\
\hline $\begin{array}{l}\mathbf{A} \\
\mathbf{B}\end{array}$ & $\begin{array}{l}1.425 \\
1.400\end{array}$ & $\begin{array}{l}4.108 \\
3.974\end{array}$ & $\begin{array}{l}2.885 \\
2.840\end{array}$ & $\begin{array}{l}\mathbf{m} \\
\mathbf{b}\end{array}$ & $\begin{array}{l}1.432 \\
4.053\end{array}$ & $\begin{array}{l}.070 \\
.243\end{array}$ \\
\hline$\overline{\mathbf{c}}$ & 1.378 & 3.796 & 2.828 & $\mathbf{x}$ & 2.832 & .037 \\
\hline D & 1.522 & 4.354 & 2.861 & & & \\
\hline $\mathbf{E}$ & 1.506 & 4.319 & 2.869 & & & \\
\hline $\mathbf{F}$ & 1.294 & 3.570 & 2.761 & & & \\
\hline G & 1.393 & 3.894 & 2.798 & & & \\
\hline H & 1.510 & 4.232 & 2.818 & & & \\
\hline I & 1.449 & 4.070 & 2.810 & & & \\
\hline J & 1.448 & 4.123 & 2.848 & & & \\
\hline
\end{tabular}


variance revealed a very slight but significant deviation from linearity simply suggests that the curvilinear (or, probably, two intersecting linear functions) may be slightly more accurate as a descriptive model. However, to argue that the linear model cannot be used to describe the $\log t / \log I$ relation would be invalid because of the tremendous significance of the linearity of regression $(\mathrm{F}=3890)$.

Let us assume two linear functions: one expressing $\log \mathrm{t}$ for the 80 and $100 \mathrm{mcal} / \mathrm{sec}$ stimuli and the other for the intensity values between the limits of 130 and $500 \mathrm{mcal} / \mathrm{sec}$. By using the estimated $\log t$ values for the eight highest intensities and transforming them back to time (seconds), one can compute the average error between the times thus derived and those derived from the empirically determined $\log t$ values. The average error amounted to $1.16 \%$. The use of this same procedure with the single straight line function resulted in an error of $1.75 \%$. The increase in precision is negligible, so we may conclude that, for radiant heat, pain threshold latencies are an inverse exponential function of the rate of heat applied to the skin.

When heat is applied to the skin surface at different rates, the underlying tissue is heated as a function of the dissipation of that heat along the skin surface, the rate of conduction inward from the surface, and the cooling capacity of the bloodstream at the site of stimulation. (The blood is now cooler than the surrounding tissues.) The exponential model allows one to state that, as the rate of heat applied to the blackened skin increases in a ratio fashion, the pain latency threshold decreases in a ratio fashion. Specifically, as the rate of heat input increases by a factor of $100 \%$ (doubles), pain threshold latencies decrease by a rate of $62.9 \%$ (approximately $3 / 5$ ).
The increase in $m$ (slope) with repeated testing simply indicates the increasing discriminative capacities of the $S$ s-the ability to discriminate among the various stimulus intensities. This increase is a common finding in psychophysical experiments and is usually considered a goal for trained Ss.

The $x$-intercept may be interpreted as an indication of a threshold of aversion. As intensity of stimulation is increased, one finds a lesser willingness on the part of $S$ to allow the heat to remain on for any length of time (Dillon, 1968). The feeling is one of a very hot, unpleasant, and sharp stab of pain-a feeling which may be considered as similar to pathologic pain. The relatively low magnitude of the (group) standard deviation at this point, indicating, as it does, a low degree of individual differences, should make it an ideal predictor for altered pain states, especially in connection with the use of analgesics.

In the earlier publication, Dillon (1968) suggested that the utilization of high-intensity stimulation should serve to reduce the criterion component in this reaction to painful thermal stimulation. The $S s$ in the current experiment had very little difficulty in determining when pain occurred at an intensity of $500 \mathrm{mcal} / \mathrm{sec}$ and relatively much more difficulty at levels of 80 to perhaps 130 or $160 \mathrm{mcal} / \mathrm{sec}$. Undoubtedly, this is reflected in the diminution in SD $\log t$ with increased intensity. There is even more diminution in this SD when one extrapolates to the $x$-intercept. This reduction in individual differences, taken in conjunction with the fact that Ss reported more intense stimuli as more painful and themselves as more certain of their responses, suggests that the criterion or reactive component in pain perception has been reduced with the use of high-intensity stimulation.
Finally, the significant increase in discriminability and the lack of change in "threshold of aversion" might also argue for relative stability of the physiological component and alterability of the reactive component through repeated exposures to the testing situation.

\section{REFERENCES}

BEECHER, $\mathrm{H}$. $\mathrm{K}$. The measurement of subjective responses. New Y ork: Oxford University Press, 1959.

BIGELOW, H., HARRISON, I., GOODELL, H., \& WOLFF, H. G. Studies on pain: Quantitative measurements of two pain sensations of the skin with reference to the nature of the "hyperalgesia of peripheral neuritis." Journal of Clinical Investigation, 1945, 24, 503-512.

D'AMOUR, F. E., \& SMITH, D. L. A method for determining loss of pain sensation. Journal of Pharmacology \& Experimental Therapeutics, 1941, 71, 74-79.

DILLON, D. J. Energy and time factors in a dolorimetric assessment of analgesic agents. Paper read at convention of Psychonomic Society, October 1965.

DILLON, D. J. Stimulus intensity, site of stimulation, and individual reactivity as determinants of the energy threshold for pricking pain. Journal of Experimental Psychology, 1968, 77, 559-566.

EKM AN, G., FRÖBERG, J., \& FRANKENHAEUSER, $M$. Temporal integration of perceptual response to supraliminal electrical stimulation. Scandinavian Journal of Psychology. 1968, 9, 83-88.

HARDY, J. D., WOLFF, H. G., \& GOODELL, H. Pain sensations and reactions. Baltimore: Williams \& Wilkins, 1952.

WERTHEIMER, M. A single-trial technique for measuring the threshold of pain by thermal radiation. American Journal of Psychology, 1952, 65, 297-298.

ZEGERS, R. T., \& CAHILL, M. C. The latency of pricking-pain sensation: 1 . The effect of Acetophenetidin and Anacin. II. The effect of repeated stimulation. Journal of Psychology, 1965, 59, 101-108.

(Accepted for publication December 26, 1970.) 